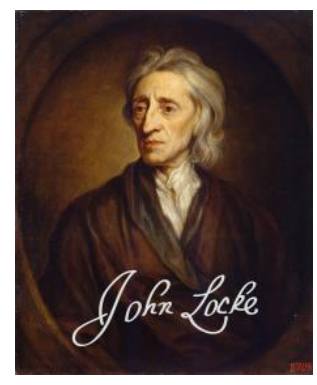

LOCKE STUDIES

Vol. 14

https://doi.org/10.5206/ls.2014.708 | ISSN: 1476-0290

Originally published: 2014

Published online: 19 FEBRUARY 2018

(C) Locke Studies, 2014

\title{
Locke, Ayers, and Abstraction
}

\section{JONATHAN WALMSLEY (LONDON)}

Recommended citation:

Walmsley, Jonathan. "Locke, Ayers, and Abstraction." Locke Studies 14 (2014): 29-58.

https://doi.org/10.5206/ls.2014.708

For more information about this article:

https://ojs.lib.uwo.ca/index.php/locke/article/view/708

Locke Studies is published by The John Locke Society.

This is an open access article published under the terms of the Creative Commons Attribution-

NonCommercial-ShareAlike 4.0 International license, which permits use, distribution and reproduction in any medium, provided the original work is properly cited and shared under the original license. 


\title{
LOCKE, AYERS, AND ABSTRACTION
}

\author{
JONATHAN WALMSLEY
}

\section{Introduction}

Berkeley famously took Locke's account of abstraction to be a process of mental separation that creates incomplete ideas which represent many individuals. A number of scholars have more recently tried to rehabilitate Locke's theory of abstraction and save it from Berkeley's criticisms. ${ }^{1}$ The most steadfast and sophisticated of these scholars is Michael Ayers, who, in a number of publications, has argued that Locke's theory of abstraction is one of 'partial consideration', where a thinker merely considers certain aspects of ideas to form universal representatives. ${ }^{2}$ I have written two papers discussing Ayers's interpretation. The first of these was concerned directly with Ayers's arguments for his reading of Locke's views on this subject, ${ }^{3}$ the second an account of the evolution of Locke's theory in the drafts of the Essay, supporting the arguments made in the first. ${ }^{4}$ In 2008, Ayers published a response to these

1 For example, J. L. Mackie in Problems from Locke (Oxford, 1976), 107-12, C. C. W. Taylor in 'Berkeley's Theory of Abstract Ideas' in The Philosophical Quarterly, 28 (1978): 97-115, esp. 99-105 and Kenneth Winkler in Berkeley: An Interpretation (Oxford, 1994), 22-52, esp. 37-43.

2 His first presentation of the interpretation was in 'Locke's doctrine of abstraction: some aspects of its historical and philosophical significance', in John Locke: Symposium Wolfenbüttel 1979 ed. Reinhard Brandt (Berlin, 1981), 5-24. It later formed a part of his Locke: Epistemology and Ontology (2 vols., London, 1991), i, 242-58. Ayers repeated his claims in Berkeley, Philosophical Works including the works on vision. Introduction and notes by M. R. Ayers (London, 1992), xxi-xxii.

3 Jonathan Walmsley, 'Locke on Abstraction: a Response to M. R. Ayers', in British Journal for the History of Philosophy 7, (1999): 123-34.

4 Jonathan Walmsley, 'The Development of Lockean Abstraction', in British Journal for the History of Philosophy 8, (2000): 395-418. 
articles, ${ }^{5}$ revisiting his earlier views, refining them in places, and sketching his own account of the development of Locke's theory of abstraction. This paper will review Ayers's new arguments to determine the further support they provide to his contention that Locke's theory of abstraction was one of 'partial consideration'. This discussion will also provide an occasion to touch on other recent scholarship on this matter.

It must be acknowledged at the outset that Ayers's interpretative instincts served him exceptionally well in identifying the passages on space in II. xiii as pertinent to the debate on abstraction. At the time he wrote, and at the time of my first article, neither of us was aware that, despite the fact that the problem of forming an idea of pure space is not directly related to the problem of universals, there was a deep historical connection in Locke's writings on these points. This was the subject of my second article: in earlier drafts of the Essay Locke had explicitly connected the process of abstraction with that of partial consideration (though there was no mention of partial consideration in those parts of the Essay dealing explicitly with universals). That Locke removed all references to abstraction in the published discussion of space seemed to indicate that he was aware that his accounts in different parts of the Essay did not match, and chose to simplify his views of both abstraction to form ideas of universals (via mental separation) and the measurement of pure space (via partial consideration).

This historical context creates additional complexity for Ayers's interpretation. Whereas he had first only to neutralise Locke's repeated and consistent descriptions of abstraction as separation in his explicit accounts of universals, he must now also explain why Locke removed reference to abstraction in the discussion of pure space in the published Essay - the passage he thought directly concerned abstraction. Ayers advances five lines

5 Michael Ayers, 'Locke's Account of Abstract Ideas-Again' in Studies on Locke: Sources, Contemporaries, and Legacy: in Honour of G. A. J. Rogers, ed. Sarah Hutton and Paul Schuurman (Dordrecht, 2008), 59-73. 
of argument to defend his interpretation in his new paper. First he seeks to denigrate any interpretation of imagist separation. Second, he attempts to co-opt Locke's descriptions of abstraction to his own ends. He next seeks a historical context that might support his interpretation of partial consideration. He then re-casts some of his original arguments in the light of earlier criticism. Finally, he reconsiders the history of the writing of the Essay so as to make his interpretation more plausible in the light of Locke's changes.

\section{Imagism and Separation}

Turning to the first line of argument, Ayers is vigorous in his description of the separation account of abstraction: it is 'bizarre', 6 reliant on 'confusion on Locke's part (apart from the intrinsic absurdity of the view')', 7 and is, at best, 'implausible'. On this last point, he and I are in agreement. Locke was an imagist, ${ }^{9}$ and a separation account of abstraction for an imagist is implausible because it requires the creation of radically incomplete images which, as commentators from Berkeley onwards have pointed out, are impossible. But that does not make it any less Locke's theory, nor does it make it any less interesting, or worthy of serious consideration. Though the Essay is arguably the foundation of modern empiricism, it contains next to nothing that a contemporary philosopher would wholeheartedly and unproblematically adopt and embrace as her own. The history of philosophy is littered with positions whose 'implausibility', even 'intrinsic absurdity', is manifest. But the evident flaws in

6 Ayers, 'Locke's Account', 67.

Op. cit., 70 .

8

Op. cit., 72 .

9 For ideas as images in the Essay, see Ayers, Locke, i, 44-51. For ideas as images in the drafts of the Essay, see Walmsley, 'Locke, Ideas and Abstraction: A Reply to Yasuhiko Tomida', in Locke Studies 7, (2007): 173-205, at 176-84. 
historically significant arguments do not detract from their philosophical import, or their part in the progress of intellectual history. Noting that a separation account is quite wrong, however robustly, is not reason enough to suppose that Locke must have held another, more plausible view.

Equally, it will not suffice to refute a separation interpretation to point out that its consequences are perverse. For instance, Ayers takes me to task for failing to parse Locke's language into plausible accounts of specific ideas. Discussing the Essay, III. iii, Ayers notes that 'Walmsley does not explain what Locke thought it would be like to have an image that is barely of a being'. ${ }^{10}$ I did not and cannot because it is impossible-but it is, nonetheless, the plain consequence of Locke's view in III. iii. 9 that 'every general term, stands for such an Idea, as is but a part of any of those contained under it'. We agree, therefore, that a separation theory of abstraction is unsound, but that fact does not determine whether Locke held such a theory - that can only be settled by a detailed review of Locke's writings on the matter.

\section{Rhetoric, Consideration and 'Partial' Ideas}

This brings us to the second strand of Ayers's arguments-his attempts to align Locke's statements about abstraction in his extended discussions of universals with a partial consideration interpretation. His first attempt at squaring Locke's words with his reading is in the discussion of the triangle in the Essay's chapter on Maxims (IV. vii. 9). Ayers cites my previous objection of his description of this passage as 'rhetorical'. 11 His case would be strengthened by noting that I had also described this passage as such in a similar discussion. ${ }^{12}$ Ayers seems to take the term in a

10

Ayers, 'Locke's Account', 64

11

Op. cit., 60, n. 4, cf. Walmsley, 'Locke on Abstraction', 130, and Ayers, Locke, vol. I, 251.

12 Walmsley, 'Locke, Ideas and Abstraction', 192. It appears that Ayers wrote his response before this paper was published, and therefore unfortunately could not take it into account in his recent article. 
wholly pejorative sense, as if rhetorical meant at least suspect or empty posturing, if not reasoning that is entirely sophistical and illusory. To my mind, rhetoric is effective persuasion, and will be so only if it is at least somewhat consonant with the reality it seeks to portray. In this case, the aim is to persuade the reader that maxims are an unlikely element of the thought of children, since simpler objects of thought, abstract ideas, are challenging to create. Locke's strategy works only if the reader is persuaded the abstract idea of a triangle is indeed difficult to frame, and thus that maxims are even less likely to be grasped and employed by children-who are, nevertheless, fully able to reason. Locke's description of abstraction in this passage is, then, rhetorical, but it is not a gross exaggeration; it is an integral part of his argument against the use of maxims. Locke may be underlining some of the difficulties attendant to abstraction to press his point, but he is not presenting an account radically different to or inconsistent with that presented elsewhere in the Essay - this is a reasonably candid description of the difficulties attendant to ideas of universals on an imagist/separation account. Should this have given Locke pause for further reflection? Doubtless, but apparently it did not.

The deeper philosophical point here is whether Locke adheres to the 'conceivability principle' described by Kenneth Winkler in his writing on this subject. ${ }^{13}$ Winkler holds that, for Berkeley, 'conceivability and possibility coincide: a state of affairs is conceivable if and only if it is possible', ${ }^{14}$ and that Locke, by a number of comments throughout the Essay, is committed to a similar position:

Locke himself accepts every one of the explicit premisses of Berkeley's case against abstraction: abstract ideas represent the impossible; what is impossible is inconsistent; and what is inconsistent cannot be conceived. ${ }^{15}$

13

Winkler, Berkeley, 30-3.

14

Op. cit., 31.

15 Op. cit., 37-38. 
Such an adherence on Locke's part would indeed condemn his account of the triangle, and Winkler asserts that Locke must therefore distinguish between 'conceiving of nothing but triangularity and conceiving of its separate existence'. ${ }^{16}$ But, Winkler notes, 'Locke will [only] be able to take advantage of this defence if he conceives of abstraction as selective attention, ${ }^{17}$ i.e. Locke must hold a partial consideration account of abstraction, rather than one of separation.

While such an interpretation might have an initial appeal, it is contingent upon Locke's agreeing to this 'conceivability principle', and, despite Winkler's assertions, that seems questionable at best, as instanced by the triangle example itself (though there will be further discussion of a separate example below). Walter Ott puts the point succinctly:

Obviously Locke is not saying that the abstract idea itself is impossible; nor does he think that particular triangles are impossible; he must then think that the determinable triangle, what we might call the content of the idea, is impossible. But clearly it is not logically impossible, like a square circle; if it were, it would also be inconceivable. Instead it violates the laws of nature: no physical thing can exist that is not fully determinate in every respect. $^{18}$

That physical impossibility is no bar to its conceivability seems plain-Locke's dialectical strategy relies upon that very point. ${ }^{19}$

Returning to his critique, Ayers seeks to undermine the import of the passage further by stating that in this passage 'Locke says

16 Op. cit., 39.

17 Ibid.

18 Walter Ott, Locke's Philosophy of Language (New York, 2004), 63.

19 Ott further undermines Winkler's point by showing that the example cited from IV. iii. 6 as the foundation of Locke's adherence to a conceivability principle merely indicated an epistemic possibility, not a logical one; cf. Ott, Locke's Philosophy, 63-64. 
nothing here about 'images' or 'imagining'. This seems an unusual line of argument since Locke is here describing the 'Idea of a Triangle', and Ayers has granted, (and I agree), that for Locke ideas are images. So when Locke says that this idea is something imperfect, that cannot exist; an Idea wherein some parts of several different and inconsistent Ideas are put together', I cannot agree with Ayers that 'Locke is not expressly telling us what it is to have an abstract idea before the mind at all'. ${ }^{20}$ Locke may not have explicitly stated that he was talking of images here, but on Ayers's own interpretation, he can be talking of nothing else. So it seems unavoidable to conclude that he is expressly telling us what he believes an idea of triangularity is. I certainly agree that a more reasonable account would be like that which Ayers describes, where 'we consider some particular or determinate perceived or imagined triangle in a partial way, focussing on its property of being triangular and employing that both as the object of our reasoning and as the standard that determines the class of things represented and being reasoned about'. ${ }^{21}$ But Locke says nothing like that in this passage, or in any other description of the process of abstraction in the published Essay.

It is true, as Ayers shortly goes on to point out, that when discussing abstraction in II. xi. 9, Locke does indeed repeatedly use the verb 'consider' in his description of the process of abstraction. So, Ayers is right that Locke's account of abstraction is a 'consideration' account-the question is what sort of consideration Locke has in mind. Ayers suggests that 'consider' here might mean 'pay attention to', or 'take into account', and this suggestion might be plausible, were such a reading not undermined by two points. The first, as previously noted in another article on this subject, is that 'consider' simply means to

\footnotetext{
20 Ayers, 'Locke's Account', 60.

21 Op. cit., 61.
} 
view or look upon attentively, ${ }^{22}$ and need have no further implication of selectivity amongst parts, or particular focus on one part, than is implied by the fact that in considering you have to consider something. The second is that in Locke's statements of what this consideration amounts to in his descriptions of abstraction, elements of ideas are considered (or 'looked upon') as 'separate', 'alone', 'precise and naked', and 'without' their concomitants, as Ayers concedes. ${ }^{23}$ This consistent qualification of 'consideration' in abstraction does not naturally consist with a 'partial consideration' or 'selective attention' account. Locke is not saying that we consider just some aspects of an idea; he says we look upon parts of ideas separate from one another.

Ayers then attempts to identify the 'consideration' in II. xi. 9, with the 'partial consideration' in II. xiii. 13, with the delightfully game 'Well, why not?' While the question might appear rhetorical, it merits an answer. Ayers notes that in III. iii. 9, Locke questions those who think that 'general Natures and Notions are anything else but such abstract and partial Ideas of more complex ones'. ${ }^{24}$ Ayers here seems to imply that since Locke has used the word 'partial', and since the ideas are 'considered', that a 'partial consideration' must be at work: 'All this surely suggests that 'partial consideration' has to be at least the first step in abstraction, and that the difference between Walmsley's view and mine must relate to what follows partial consideration'. ${ }^{25}$ I am not sure that these linguistic similarities are sufficient to make this determination, but a similar conclusion has also been advanced by Walter Ott, an otherwise staunch defender of the separation interpretation of abstraction, on what might be considered more substantive grounds. Ott suggests that while

Walmsley, 'Locke, Ideas and Abstraction', 190, cf. OED, 1 and 2.

23

Ayers, 'Locke's Account', 63.

24 Ibid.

25 Ibid. 
Locke does indeed form abstract ideas by separating the components of a complex idea into simpler constituents, this separation requires a form of selective attention or partial consideration as a pre-requisite:

Locke holds that one gains an idea of white, for example, by separating it from its concomitant ideas. This presupposes selective attention in that before one can separate idea $\mathrm{A}$ from ideas $\mathrm{B}$ and $\mathrm{C}$ one must first have the complex idea $\mathrm{ABC}$ and selectively attend to $\mathrm{A}$ before one is in a position to separate $\mathrm{A}$ from $\mathrm{ABC}$. So abstraction, on my view, requires but is not identical with selective attention. ${ }^{26}$

Both Ayers and Ott seem to me to ignore what Locke actually says about the process of abstraction. Perhaps unsurprisingly for someone whose entire theory of mind is based on the direction perception and manipulation of images, the account appears based on direct observation. In a child, for example, 'The Ideas of the Nurse, and the Mother, are well framed in their Minds; and, like Pictures of them there, represent only those Individuals'. ${ }^{27}$ These pictures are then used as a basis for further comparison:

Afterwards, when time and a larger Acquaintance has made them observe, that there are a great many other Things in the World, that in some common agreements of Shape, and several other Qualities, resemble their Father and Mother, and those Persons they have been used to, they frame an Idea, which they find those many Particulars do partake in; and to that they give, with others, the name Man, for Example. ${ }^{28}$

Locke seems to have in mind less a 'partial consideration' of certain aspects, and more a direct comparison of different ideas which are seen to agree with each other-Mother, Father, the

26 Ott, Locke's Philosophy, 58.

27 John Locke, An Essay concerning Human Understanding, ed. P. H. Nidditch (Oxford, 1975), III. iii. 7, 411.

28 Ibid. 
Nurse and all these other people can be literally observed to look alike. It is this visible observed agreement that is the foundation of the abstract idea - the child can simply see the resemblance, and discards all those elements that don't contribute to it. Selective attention does not seem to feature. Rather than seeing $\mathrm{ABC}$ and selectively considering just $\mathrm{A}$ before removing it, on Locke's account the child sees ABC, ADE and AFG, then simply sees $A$ repeated amongst them all and removes everything else from these ideas to leave A alone. Locke is clear that the process of abstraction is a removal of elements to leave a set of remnants:

Wherein they make nothing new, but only leave out of the complex Idea they had of Peter and James, Mary and Jane, that which is peculiar to each, and retain only what is common to them all. ${ }^{29}$

The same sort of mental visualisation would seem to underpin Locke's theory of knowledge - the perception of the agreement of disagreement of ideas-you can literally see that white is not black, and therefore know that that is the case. ${ }^{30}$

Further, a 'Partial Idea' is certainly not identical to an idea partially considered. The former is an idea that is incomplete, and but a part of another, the latter is a whole contemplated in some respect. A diagram partially considered, and a partial diagram, are two very different things. Indeed, a neat summation of Locke's view on what 'partial' means in this context might be found in one of the section descriptions for the chapter 'Of the names of Substances': 'The more general our Ideas are, the more incomplete and partial they are'. ${ }^{31}$ In the context of universals, 'partial' and 'incomplete' are synonyms. Ayers is working hard to combine elements from different parts of Locke's discussions of abstraction to equate to his 'partial consideration' account, but the

29 Ibid.

Essay, IV. i. 2, 525.

31 Essay, III. vi. 32, 459. 
materials seem unwilling to bend to his will, most likely because they simply weren't designed to Ayers's purposes.

\section{The Port Royal Logic and 'Consideration'}

Ayers next turns to Locke's description in III. iii. 7-9, of abstraction as 'leaving out' parts of ideas of individuals, and 'retaining' only those elements common to all, noting that his interpretation might be 'ruled out' by such language. ${ }^{32}$ This leads him to the third line of argument, that of attempting to place Locke's remarks on abstraction in their historical context, and, in particular, in his reading of the Port Royal Logic a few years after completing Drafts A and B of the Essay. Ayers draws attention to the Logic's account of universals where 'we achieve understanding by means of abstraction when a thing has various attributes, but we consider just one of them, setting aside the others, ${ }^{33}$ and then cites its account of forming the general idea of a triangle:

having drawn on paper an equilateral triangle, if I confine myself to the consideration of it in the place where it is, with all the accidents which determine it, I shall have the idea of that triangle alone; but if I detach my mind from the consideration of all these particular circumstances, and consider only that it is a figure bounded by three equal lines, the idea which I form of it will, on the one hand, represent to me more accurately that equality of lines; and, on the other, will be able to represent to me all equilateral triangles. And if, not restricting myself to that equality of lines, but proceeding further, I consider only that it is a figure bounded by three right lines, I shall form an idea which will represent all kinds of triangles. If, again, not confining myself to the number of lines, I simply consider that it is a plane surface, bounded by right lines, the idea which I form will represent all rectilineal figures; and thus, step by step, I am able to ascend to extension itself. ${ }^{34}$

32

Ayers, 'Locke's Account', 63-64.

33

Op. cit., 64.

34 Antoine Arnauld and Pierre Nicole, Logic, or, The Art of Thinking: Being The Port-Royal Logic, trans. T.S. Baynes (Edinburgh, 1850), 46-47. 
This is an interesting account of abstraction, and it is worth noting that Locke was aware of it, but I am not convinced it is as significant as Ayers suggests.

In the first instance, this was certainly not his account in the published Essay. Locke does not talk about considering only some aspects of an idea, or detaching his mind from consideration of particular circumstances. Nor does he say that we 'consider length without paying attention to breadth', as the Logic suggests geometers do, and Ayers intimates Locke might in this context. ${ }^{35}$ Locke talks of considering ideas separate from their concomitants, leaving things out of ideas, and retaining only parts of them.

Secondly, 'consideration' in this context was hardly confined to the Logic alone. As I noted in the account of the development of Locke's abstraction, St. Thomas Aquinas used broadly similar language in his account of universals. ${ }^{36}$ Equally, even Descartes occasionally used similar phrasings in his discussions of universals. ${ }^{37}$ Thirdly, and more pertinently, we should note that Locke himself talked of 'consideration' concerning ideas of universals in Drafts A and B of the Essay, written before he had read the Logic. So, for example, in one of Locke's earliest

35

Op. cit., 46, cf. Ayers, 'Locke's Account', 63.

36

'[I]f we consider colour and its properties, without reference to the apple which is coloured, or if we express in word what we thus understand, there is no error in such an opinion or assertion', and 'that humanity be apprehended without the conditions of individuality, that is, that it be abstracted and consequently considered as universal, befalls humanity inasmuch as it is perceived by the intellect', in Thomas Aquinas, Summa Theologiae, ed. and trans. Thomas Gilby et al. (London 1964-1980), I q85 a1 and a2, cf. Walmsley, 'Development', 396-97.

37

'Thus, when I consider a shape without thinking of the substance or extension whose shape it is, I make a mental abstraction', Descartes to Gibieuf, 19 January 1642, in The Philosophical Writings of Descartes, ed. J. Cottingham, R. Stoothoff and D. Murdoch, (3 vols., Cambridge 1984-91), iii, 202. '[T] his species is the real extension of a body considered in abstraction from everything else about it save its having a shape', in op. cit., i, 58 . 
statements of how we attain to the most universal ideas, he uses the following phrasing:

Now the notion of one [is] suggested by every object of sense \& also every act or operation of the minde, which is noething but the consideration of that thing alone without joyning or reference to any other ${ }^{38}$

This sentiment was repeated, with some alterations, in Draft B. ${ }^{39}$ Equally, in Draft B, when discussing the legitimacy of our definitions of species, Locke notes that the understanding

can only come to have true notions by considering \& collecting those simple Ideas it findes in particular things \& by that means frame generall notions \& generall names.

Here, generality seems to come from a consideration of certain aspects of particular things. As previously demonstrated, Locke had no consistent theory of abstraction in the early drafts of the Essay. ${ }^{41} \mathrm{He}$ was nonetheless aware that 'consideration' was a possible means of forming ideas of universals.

So I would agree with Ayers that Locke would doubtless have been interested in the Logic's treatment of the issue when he read the book, and furthermore would have already been familiar with the language used to solve the problem of universals. But he did not adopt this language when he later came to write his own account of abstraction in Draft C, nor in the published Essay. Nor, it should be noted, does Ayers suggest that this is the case-his point seems less to directly identify the Logic's account with

38 John Locke, Drafts for the Essay concerning Human Understanding, and other Philosophical Writings, ed. P. H. Nidditch and G. A. J. Rogers, (Oxford, 1990) (henceforth Draft A or B) Draft A, §12, 24.

39

Draft B, §50, 156, cf. Walmsley, 'Development', 409.

40

Draft B, §86, 193, cf. Walmsley, 'Development', 409.

41 Walmsley, 'Development', 398-410. 
Locke's own, and more to create an historical mood music conducive to a 'selective attention' or 'partial consideration' interpretation. It is questionable how much this advances his case that Locke's talk of 'leaving out' and so forth is consistent with his interpretation.

\section{Memory, Reasoning and 'Particular' Ideas}

As Ayers concedes at the opening of his next paragraph, 'the question remains, if ideas are for Locke essentially sensory...how can he adopt such a conception of abstraction without abstract ideas ending up as abstract, partial images? ${ }^{42}$ Ayers turns now to the fourth line of argument-re-casting arguments from his original account of abstraction in his book Locke. There Ayers had argued from the fact that ideas serially recalled from memory were tokens of the same type to the conclusion that these idea tokens had to be ideas of tokens i.e. ideas of individuals. ${ }^{43} \mathrm{He}$ acknowledges that my arguments on this point have given him an opportunity to clarify his own line of reasoning, ${ }^{44}$ and that he will reformulate his views accordingly.

He turns first to Locke's account of memory, noting that we share a dispositional view of ideas-i.e. that ideas when not before the mind, can be recalled to it by the memory, and that abstract ideas are "laid up' by the understanding 'with names commonly annexed to them". $45 \mathrm{He}$ is therefore correct that the question of whether what is 'laid up' in the memory is an image does not arise-it is a disposition, not an idea. Ayers proceeds to speculate as to what might be 'laid up' in the memory. He first notes Aaron's view that it is 'just enough remembered content to

\footnotetext{
42

Ayers, 'Locke's Account', 65.

43

Ayers, Locke, i, 249-50.

44 Walmsley, 'Locke on Abstraction', 125-27.

45 Ayers, 'Locke's Account', 66.
} 
determine the meaning of the general term in question, ${ }^{46}$ and then Mackie's view that 'Locke is offering an account of the psychological process involved in the acquisition of those recognitional capacities that permit the use of general terms'. ${ }^{47}$ Neither line is inapposite, Ayers asserts, but neither 'moves on to a satisfactory explanation of the positive function of Locke's account of abstraction within his theory of knowledge'. ${ }^{48}$ As briefly alluded to above, the separation interpretation is dismissed as 'bizarre', leaving Ayers to conclude:

My own understanding of Locke's account has been, and remains, that what is before the mind in universal reasoning is for Locke simply the same kind of thing as what was before the mind in the process of abstraction involved in the acquisition of the general terms in question: that is to say, determinate objects of sense or imagination, 'partially considered' with respect to the features marked by those terms.

This certainly clarifies Ayers's current position, but it is not clear to me how this position has been bolstered by a consideration of memory and recollection. The dispositional power of memory (I hope Ayers will concede) must apply equally to ideas of particular things as to ideas of universals, both sets of which are 'laid up' in the memory with names annexed to them, and which can be recalled when not actually before the mind. Ideas of particulars in the memory, therefore, are no more or less images than ideas of universals. And it makes no more sense to speculate about what ideas of particulars are in the memory than it does to speculate about general ideas - neither have content, imagistic or otherwise, on Locke's account; both are merely the products of the

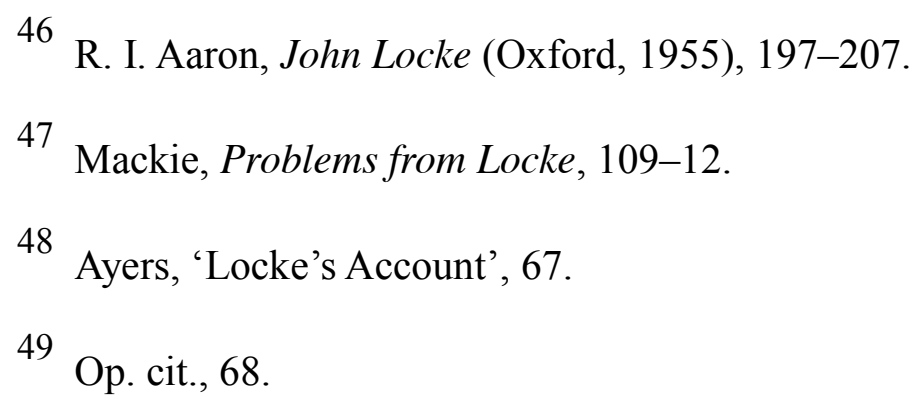


disposition to recall. So I agree with Ayers when he continues that 'Actual or particular abstract ideas are the same sort of thing both before their 'laying up', or commitment to memory, and after their 'revival' or recall (or, for that matter, their recognition in reality), ${ }^{50}$ But I would add that the same is true of ideas of particular things, and that this fact does not decide the question of what these ideas are before or after their recollection. Memory and recollection, therefore, seem to me at best orthogonal to the question of abstraction, and do not provide additional support to Ayers's 'partial consideration' reading.

Ayers then turns his attention to Locke's statements that ideas of sense can form the basis for general reasonings, rightly noting that 'The Lockean child can perceive a relation between ideas received in sensation even before speech, knowing, for example, 'that Sweet is not Bitter'. 51 He further points out Locke's preference for diagrams in mathematical reasoning, as supporting his contention that 'objects of general reasoning can be, and often usefully are, objects of current sense-perception'. ${ }^{52}$ The question here, though, must be what Ayers thinks Locke really means in these cases. Does he think that the child believes this sweet thing is not the same as that bitter thing, or does he believe that the child thinks 'sweet' is not the same as 'bitter'? Does he think that the visible mathematical demonstration applies in this case, or in all cases of the same type? Ayers supplies a useful means to test this point further, citing one of Locke's own examples - 'the child comes to know the truth that three and four make seven 'upon the same Grounds, and by the same means, that he knew before, That a Rod and Cherry are not the same thing". ${ }^{53}$ However you parse it, the ideas of 'three', 'four' and 'seven' here mentioned must be

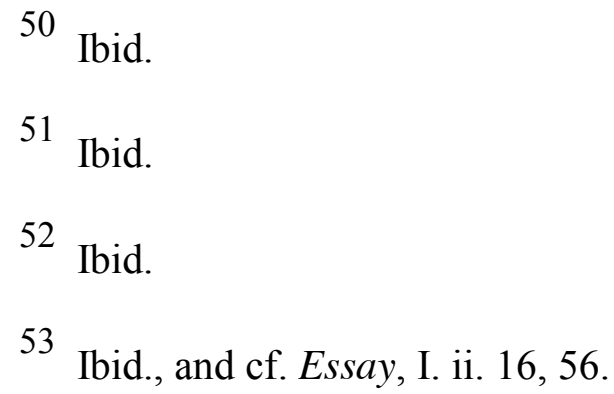


abstractions. Indeed, Locke opens the section by stating that 'A Child knows not that Three and Four are equal to Seven, till he comes to be able to count to Seven, and has got the Name and Idea of Equality'. ${ }^{54}$ In this instance, then, not only does the child have to acquire the ideas of number, she must have acquired and named the very abstract concept of 'Equality'. Ideas of sense may be the foundation of the child's reasoning about number, but not solely as raw or unprocessed ideas of particulars. A child may well know that this rod is not that cherry, but if she agrees that rods are not cherries, she is discussing ideas of universals, the products of abstraction, not just the individual ideas they might have of this stick and that fruit. So too with diagrams in mathematics. As Ayers quite rightly points out, 'Sensible particulars can be made use of in determining universal relations', ${ }^{55}$ but they are the input of the process, not its outcome-as Ayers continues: 'What makes the reasoning universal is that the perceived objects are abstractly considered in some respect, and employed as representative of a corresponding class'. 56 The question is just what this 'abstract consideration' amounts to, and just how sensible particulars are translated into general truths. Noting that sensible ideas are an input does not mean that they are the output also - that is the very question at issue.

Ayers tries to further bolster his line of reasoning by noting that abstract ideas are particular things, quoting Locke:

the immediate Object of all our Reasoning and Knowledge, is nothing but Particulars...the Perception of the Agreement, or Disagreement of our Particular Ideas, is the whole and utmost of all our Knowledge. Universality is but accidental to it, and consists only in this, That the

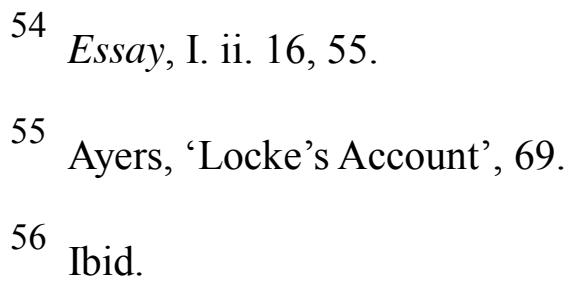


particular Ideas, about which it is, are such, as more than one particular Thing can correspond with, and be represented by. ${ }^{57}$

Ayers continues:

Locke's argument here requires that abstract ideas are particular in just the same sense as he is claiming the premise of a syllogism can be particular, and that claim is not the truism that if one thinks the premise, the thought will be a particular mental act. ${ }^{58}$

Locke's argument does indeed require that abstract ideas are particular things, but again, that has no bearing on their content, and it certainly does not require that they be ideas of particular things. Locke is clear that there are 'general' terms and 'general' ideas, spelling out in detail how these are created. Reading this passage to imply that 'particular Ideas' must mean 'ideas of particulars', rather than 'specific ideas' seems implausible - the latter is a perfectly conceivable reading, and one consistent with what Locke says elsewhere. Ayers claims that reading this passage alongside that concerning mathematics noted above makes the separation interpretation implausible, but I must admit to being unpersuaded by the conjunction. A separation interpretation requires that abstract ideas are particular things (though not ideas of particulars), and Ayers himself has conceded that, even though sensible particulars are the starting point of general reasoning, 'abstract consideration' (whatever we believe it amounts to for Locke) is required to undertake general reasoning.

I am further unpersuaded by Ayers's contention that 'there is nothing intrinsic to ideas before the mind in virtue of which they are used as general signs-universality is a purely relational property of ideas', 59 citing Locke's statement that

\footnotetext{
57

Essay, IV. xvii. 8, 680-81. Cf. Ayers, 'Locke's Account', 70.

58

Ayers, 'Locke's Account', 70.

59

Ibid.
} 
When therefore we quit Particulars, the Generals that rest, are only Creatures of our own making, their general Nature being nothing but the Capacity they are put into by the Understanding, of signifying or representing many particulars. For the signification they have, is nothing but a relation, that by the mind of Man is added to them. ${ }^{60}$

Ayers's argument would be more convincing had this been the sum total of what Locke said on the subject of abstraction-but this passage comes immediately after Locke has spelt out in great detail the process by which these 'creatures' were made, and how this capacity is bestowed upon them; that is to say, by taking ideas of particulars, and 'separating them' from their concomitants, 'leaving out' some parts, and 'retaining' only what is common to several individuals. ${ }^{61}$ It seems implausible to suppose that Locke's account of abstraction was fundamentally transformed in the handful of intervening paragraphs. It should be further noted that it was their 'signification' that Locke said was nothing but a relation, not, as Ayers contends, that their newly acquired status and content after the process of abstraction was itself purely relational.

Walter Ott provides a useful explanation of the point, noting that, for Locke, the role of idea as intermediary between mind and world explains this relation:

our ideas themselves are particular, but when they range over a number of other particulars, they can be said to be universal, and our knowledge with them. This universality is not a property of the ideas themselves; it consists in the relation of agreement between the idea and other particulars. Nevertheless, the ideas in question must have the intrinsic property of being able to represent particulars. ${ }^{62}$

60 Essay, III. iii. 11, 414.

61 Essay, III. iii. 6-9, 410-12.

62 Ott, Locke's Philosophy, 56-57. 
Ott then explains the nature of this relation: 'Ideas are general, that is, they apply to more than one thing, when we craft them in such a way that they represent many particulars', which, in turn, 'must have a foundation in the intrinsic character of the idea's intentional object: if an idea represents dogs, its content must in some way 'conform' to dogs'. ${ }^{63}$ In short, there is an idea, and its history, character, and the role we make it play gives it a relational signification - but it does not thereby reduce or deflate generality to nothing but a relation between particulars and an idea of a particular. Indeed, such an interpretation would be at odds with Locke's repeated statements about the unique process for creating, storing and using abstract or general ideas.

Ayers's final re-casting of his original arguments concerns 'the general question of what are denoted by Locke's expression 'particular ideas', and of how the class of 'particular ideas' is related to that of "ideas of particulars". ${ }^{64}$ Ayers claims that, in this context, 'it makes... sense to take Locke's 'ideas' to be ideas taken 'objectively'...To perceive a relation between the idea of the angles of a triangle and the idea of the angle on a straight line is to perceive a relation between two objects of thought, not two acts of thought'. ${ }^{65}$ He then continues:

On that understanding of what an idea is, a particular idea is a particular object of thought... So on that understanding, a particular idea is the idea of a particular. $^{66}$

This inference merits scrutiny. As far as I can see, that some mental entity is a particular object of thought in no way implies that that entity must be of a particular thing. Consider an

63

Op. cit., 57.

64 Ayers, 'Locke's Account', 71.

65 Ibid.

66 Ibid. 
analogous example outside Locke's theory of mind, for example the concept of the number seven. I would presume that Ayers would say that this is an object of thought, and that it can be related to other objects of thought. Re-running Ayers's line of reasoning in this case, we could say that on that understanding of what a concept is, a particular concept is a particular object of thought. But we would surely hesitate to say that therefore the particular concept of seven is the concept of seven particular things - say, Sneezy, Sleepy, Dopey, Doc, Happy, Bashful and Grumpy. Returning to the case of Locke's ideas, I see no reason to not find the reasoning equally implausible. The particular abstract idea of two (whatever it may be) may be granted a particular object of thought, but we surely need not say that it is therefore necessarily, and on this ground alone, an idea of two particular things. As Ott notes in a similar context,

[w]e must distinguish between the properties of the idea (e.g., it exists in a mind, it is thought of at this moment, or what have you) from the properties the idea represents. An idea as a mental object is always fully determinate and particular. But what it represents need not be. There is in general no inference from the properties of a representation to those of what is represented. $^{67}$

I would therefore suggest that, taken in the round, Ayers's re-casting of his arguments has not further advanced his interpretation.

Ayers's argument is not helped by his next citing the passage from Draft B which appears to directly undermine his overall case. ${ }^{68}$ There each idea of things like 'blew or bitter' are presented as 'one single numericall thing [that] agrees to \& represents all the qualities of that kinde where soever existing'. ${ }^{69}$

67

Ott, Locke's Philosophy, 57.

68

Cf. Walmsley, 'Development', 407.

69

Draft B, §59, 161-62, cf. Walmsley, 'Development', 407. 
Ayers is correct to say that "Walmsley...believes that this passage fits seamlessly in with the later explanation of abstraction, which he takes to be an explanation of how it is that representative simple Ideas can stand absolutely alone in the mind'. ${ }^{70} \mathrm{He}$ is right not least because, as far as I can determine, nothing Locke says in the published Essay is inconsistent with this statement, and, indeed, it seems consonant with the general tenor of Locke's description of abstraction there, and more broadly with his general tack throughout the Essay of describing all ideas, of either particulars or universals, as specific individual things, with specific individual names allocated to them. Ayers, at least, offers no clear rebuttal of such an interpretation, or any grounds for stating it is inconsistent with Locke's statements in the published Essay, simply noting instead 'I find that implausible'.

\section{The Drafts of the Essay}

The consideration of this passage from Draft B does, however, prompt Ayers to address the historical question of why Locke altered the passages in Draft $\mathrm{C}$ regarding pure space to remove any reference to abstraction. Ayers notes that my description of the historical evolution of Locke's theory of abstraction was 'ingeniously plausible'. ${ }^{72}$ While the account certainly seems plausible to me, I might respectfully differ with the assertion of ingenuity on this account - the paper simply laid out all the references Locke made to abstraction in the writing of the Essay in roughly chronological order; the story rather tells itself. Anyone undertaking the same exercise would have noted that Locke removed the references to abstraction from the Essay's chapter on space. Given the palpable inconsistency between the account of abstraction in the chapter on that point in Draft $\mathrm{C}$, and

\footnotetext{
70 Ayers, 'Locke's Account', 71.

71 Op. cit., 71-72.

72 Op. cit., 62.
} 
the remarks on space, the reason why Locke might have done this also seems reasonably clear.

Ayers, however, seeks to present an alternative account which, he admits, is 'to an extent speculative'. Locke removed reference to abstraction in the remarks on space

since his official account of abstraction, as he wished to use the term, included both commitment to memory and the employment of abstract (i.e. abstractly considered) ideas as representatives in universal thought, it would be inappropriate to employ the term for the kind of partial consideration of an indivisible whole that was involved in the measurement of $^{\text {space. }}{ }^{73}$

He thinks also that Locke did there retain a point in these remarks to highlight what he thought impossible:

the consideration of 'the mobility of body without its extension, without thinking of their separation'-without thinking of them, as he goes on to say, 'as existing separately'. This last gloss distinguishes the conception of mental 'separation' he was opposing to partial consideration from the conception employed just before, in section 11. For there, having remarked that 'solidity cannot exist without extension', he had said that they are nevertheless 'wholly separable in the Mind one from another'.

I can agree with Ayers's first point to an extent- the measurement of pure space was a very different problem than that of universals, and, even setting memory and universal representation aside, there is no relation between the two and no obvious need to mention them together. ${ }^{75}$ Since Locke never mentions abstraction in any context other than universals in the

73

Op. cit., $72-73$.

74

Op. cit., 73.

75 Winkler provides an interpretation of this passage similar to Ayers's in Berkeley, 38-40. Ott notes the uniqueness of the idea of pure space and the nature of division in conceiving its parts in Locke's Philosophy, 60-63. 
published Essay, it seems clear that discussion of it in remarks on space would have been somewhat anomalous.

The second point seems to me mistaken. Let us turn to look at the entirety of Locke's later quote, which Ayers thinks clinches his interpretation:

a partial consideration is not separating. A Man may consider Light in the Sun, without its Heat; or Mobility in Body without its Extension, without thinking of their separation. One is a partial Consideration, terminating in one alone; and the other is a Consideration of both, as existing separately. ${ }^{76}$

Locke says that you can consider 'Mobility in Body without its Extension, without thinking of their separation'. But he then goes on to draw a contrast between that mode of thinking, and separation simpliciter: 'One is only a partial Consideration, terminating in one alone; and the other is a Consideration of both, as existing separately'. Locke does not say that mental separation is impossible, or that he was 'opposing' such a process, as Ayers suggests; on the contrary he articulates the difference between partial consideration (terminating in one alone), and the different, and apparently perfectly acceptable, act of mental separation (a 'Consideration of both, as existing separately').

Moreover, stating that some ideas have others as their necessary components does not mean that it is impossible to separate some ideas from their concomitants in all cases. The issue with an imagist account of abstraction is not that you try to form abstract ideas without all concomitants, it is that many of the remaining concomitants are not determinate. No one, for example would form an abstract idea of motion without space, though you can certainly think of space with nothing moving in it, making it clear the ideas are distinct and 'wholly seperable in the Mind one from another'. Equally, no one would form the abstract idea of a human without height, since this is an integral part of the human shape-you can't have a shape without dimension. The problem

76 Essay, II. xiii. 13, 173. 
for an imagist is that the idea of the human shape should have no specific, particular height, and it is impossible to have an image with a radically indeterminate height. So too with the colour: no-one supposes that men have no colour, but the image of a man cannot be all the possible colours that men can be, nor can it be without colour. Turning to the examples given in II. xiii. 11-13, you could say that it is indeed impossible to think of, or form, any sort of idea of motion without space, but who would do such a thing, since you can't move without space to move in? Similar reasoning applies to colour and extension. But you certainly can think of light existing separately from heat in the sun, since the light does not require the heat in either thought or reality. That some subsets of ideas are inseparable in both thought and existence is no bar to mental separation per se; that bar only becomes apparent when it is supposed that all these ideas are actually images.

So, the statement that 'Motion can neither be, nor be conceived without Space' is not an in principle bar to the formation of an abstract idea of motion; Locke would not separate motion from space in his abstract conception. Where he would get in trouble, though, would be in forming an idea of motion that had a radically indeterminate image of space with no particular dimension, or, indeed, trying to create an image of something moving, when that something is nothing in particular. So too with the example of solidity and extension cited by Ayers.

That said, it is worth bringing to bear at this point a passage not previously noted in this debate, which sheds further light on the discussion of matter, body and extension, and does so specifically in the context of general terms. In the Essay's chapter 'Of the Abuse of Words', Locke commences his discussion as follows:

How much names taken for Things, are apt to mislead the Understanding, the attentive reading of philosophical Writers would abundantly discover; and that, perhaps, in Words little suspected of any such misuse. I shall instance in one only, and that a very familiar one. How many intricate Disputes have there been about Matter, as if there were some such thing 
really in Nature, distinct from Body; as 'tis evident, the Word Matter stands for an Idea distinct from the Idea of Body? ${ }^{77}$

Locke notes that this distinction is obvious in the fact that the words cannot be indifferently substituted for each other. He then enquires why this is so:

though Matter and Body, be not really distinct, but where-ever there is the one, there is the other; Yet Matter and Body, stand for two different Conceptions, whereof the one is incomplete, and but a part of the other. For Body stands for a solid extended figured Substance, whereof Matter is but a partial and more confused Conception, it seeming to me to be used for the Substance and Solidity of Body, without taking in its Extension and Figure. $^{78}$

Matter and body are not separable in reality, but their ideas are distinct, with one being 'incomplete, and but a part' of the other. Locke then goes on to identify this as a 'partial' and more confused conception, supporting the contention above that when Locke speaks of 'partial Ideas' in respect of abstraction he is not speaking of considering just aspects of ideas, ${ }^{79}$ but rather, making some ideas that are 'incomplete, and but a part' of another. Locke notes that this incompleteness of the idea of matter in comparison to body is what explains our inability to interchange the terms. $\mathrm{He}$ is clear, however, that this incompleteness pertains only to our ideas, and not to reality:

But since Solidity cannot exist without Extension, and Figure, the taking Matter to be the name of something really existing under that Precision, has no doubt produced those obscure and unintelligible Discourses and Disputes, which have filled the Heads and Books of Philosophers concerning Materia prima; which Imperfection or Abuse, how far it may

\footnotetext{
77 Essay, III. x. 15, 498.

78 Ibid.

79 Essay, III. iii. 9, 412.
} 
concern a great many other general Terms, I leave to be considered. ${ }^{80}$

Locke seems here to imply that even though solidity cannot exist without extension and figure, there is no bar to separating these ideas and creating the idea of matter from the former alone. This would seem to undermine Ayers claims that Locke's 'partial consideration' was designed to solve the problem of creating ideas of things that can't exist-Locke here, as elsewhere in his account of abstraction, seems content to explicitly embrace ideas that are 'incomplete, and but a part' of another, in this extreme case, apparently despite their actual (or imagined) impossibility. This example would also seem to further undermine Winkler's claim, noted above in the discussion of the triangle from IV. vii. 9, that Locke adhered to the 'conceivability principle'. Locke seems perfectly content with the notion that you can have a 'partial' and 'incomplete' idea like 'Matter' which is obviously not the name of 'something really existing under that Precision'. The same would apply to the abstract idea of the triangle, which is 'something imperfect, that cannot exist'. All of which would support Ott's contention that 'Locke must therefore distinguish between nomological and logical impossibility: determinable triangles are not logically inconsistent but prohibited from existing outside the mind, presumably by the laws of nature'. ${ }^{81}$

How Locke thought he might reconcile such remarks with his earlier contention that, 'Many Ideas require others as necessary to their Existence or Conception, which yet are very distinct Ideas [for example] Motion can neither be, nor be conceived without Space', ${ }^{82}$ is not immediately clear. It may be that Locke was here taking the extreme position of those with whom he did not agree (though he does not explicitly say that such practices are outright

\footnotetext{
80

Essay, III. x. 15, 498-99.

81

Ott, Locke's Philosophy, 63.

82

Essay, II. xiii. 11, 172.
} 
impossible). Perhaps a hint of disassociation can be found in his calling 'Matter' in III. x. 15 a 'Conception', where objects of thought in the Essay are usually called 'Idea'. Since this 'Matter' was an attempt to create an idea of solidity apparently without extension or figure at all (rather than just no specific extension or figure), when 'Solidity cannot exist without Extension, and Figure', it was a suspect, perhaps even sophistical, 'Conception', an example of 'names taken for Things', rather than a more trusted and legitimate 'Idea'.

In any event, it is far from clear that Ayers's interpretation of II. xiii. 11-13 shows that Locke rules out 'separation', and that 'partial consideration' must therefore be his preferred mode of forming ideas of universals (despite the fact that he always talked of separation when discussing abstraction). So while I certainly can agree with Ayers that separation is a very bad theory of abstraction for an imagist to hold, and I am sympathetic to his conclusion that Locke's account of abstraction makes coherent sense if and only if 'what he had in mind as 'separating' was...considering [i.e. paying selective attention to] distinct ideas separately, without thinking of their objects 'as existing separately", 83 unfortunately this does not appear to be the theory of abstraction that Locke himself published in the Essay.

\section{Conclusion}

Ayers's defence of his interpretation, and its careful retrenchment in the light of criticism, is subtle, sustained, and strenuous. His desire to rescue Locke from error is admirable and, as noted at the outset, his philosophical instinct in inferring a connection between the account of space and that of abstraction was incisive and impressive. Nonetheless, I fear that the arguments he advances cannot support the conclusion that he wishes to draw. Pointing out that a theory of abstraction as separation for an imagist is a bad idea does not mean Locke cannot have held such a theory. Locke descriptions of abstraction in the Essay simply

83 Ayers, 'Locke's Account', 73. 
can't be bent into a partial consideration account (not least because, as we can see in the move from Draft C to the Essay, Locke well understood that the two were different). Noting that Locke read the somewhat more plausible Port Royal Logic account of abstraction does lend interesting historical context to the discussion, but really only further serves to highlight that Locke did not adopt such an account in the published Essay. The storing of ideas in the memory is at best tangential to abstraction - ideas of both particulars and abstractions are stored there and the content of neither is determined by this storage. Equally, there is nothing to suggest that general reasoning for Locke must, of necessity, be undertaken with ideas of particular things, or that 'particular ideas' must be 'ideas of particulars'. Finally, while it is perhaps plausible to suppose that Locke might have ceased talking of abstraction in connection to space in the published Essay because the subject matters were quite heterogeneous, it was not because he thought mental separation of images impossible. Locke's avowed account of abstraction is patently predicated on the separation of the elements of images - he says so time and again. Moreover, in some instances Locke even seems happy to countenance the mental separation of ideas that could not possibly be separated in existence, namely Matter and Body. In short, Ayers's attempts to rehabilitate Locke's account of abstraction, while understandable and admirable, are ultimately unsuccessful - the Drafts and the published Essay show that Locke, even if he didn't quite realise the mess he was getting himself into, got into it quite deliberately. As the most sustained and sophisticated of Locke's would-be rescuers, we might consider Ayers the best defender of the partial consideration interpretation, and his falling short on this score to definitively settle the matter in favour of a separation interpretation.

This, however, would be premature. Locke composed numerous philosophical works outside the Essay proper-most notably in response to his critics and in various abridgements of the Essay, many written after the Essay's publication. These 
provide several extended discussions of the nature and output of abstraction, and furnish an independent means to test interpretations of Locke's mature views on the matter. An examination of these sources, largely overlooked in this debate, is the subject of the subsequent paper.

London 